\title{
Interaction of Folk Medicinal Plants with Levofloxacin against Escherichia Coli
}

\author{
Isra Tayseer ${ }^{1 *}(\mathbb{D})$, Hanan Azzam ${ }^{2,3}$ (D), Nehaya Al-Karablieh ${ }^{2,4}(\mathbb{D})$, Amal Mayyas ${ }^{5}$ (D) \\ and Talal Aburjai ${ }^{1}$
}

${ }^{1}$ Department of Pharmaceutical Sciences, School of Pharmacy, The University of Jordan, Amman, Jordan. ${ }^{2}$ Hamdi Mango Center for Scientific Research, The University of Jordan, Amman, Jordan.

${ }^{3}$ Department of Chemistry, Faculty of Science, The University of Jordan, Amman, Jordan.

${ }^{4}$ Department of Plant Protection, School of Agriculture, The University of Jordan, Amman, Jordan.

${ }^{5}$ Faculty of Health sciences, American University of Madaba, Madaba, Jordan.

\begin{abstract}
The present study was conducted to assess the in vitro activities of folk medicinal plants in combination with levofloxacin against TG1 and mutant KAM3-1(DacrB- $\Delta$ tolC) Escherichia coli strains. Plants were chosen based on their traditional use in combination with antibiotics among laymen. Standard protocols were followed to examine the antimicrobial activity of plant extracts and levofloxacin against E. coli in term of their minimum inhibitory concentrations (MICs) and to evaluate the plant extractslevofloxacin interaction using checkerboard method. Among the twelve plants investigated, Thymus vulgaris, Zingiber officinale, Teucrium polium, Matricaria chamomilla and Curcuma longa had the best antimicrobial activities against $E$. coli strains with MIC values at $250 \mu \mathrm{g} / \mathrm{ml}$. It is noteworthy to mention that other folk plants extracts reveled no effects against $E$ coli strains. Furthermore, additive interactions were observed between levofloxacin and $T$. polium or $T$. vulgaris against $E$. coli wild-type TG1 strain. There was no antagonism being observed in this study. The detection of additive interaction between the extracts and levofloxacin demonstrates the prospective of these folk medicinal plants as a source of compounds to modulate antibiotic resistance.
\end{abstract}

Keywords: Interaction, Escherichia coli, levofloxacin, antibiotics, Minimum inhibition concentration, checkerboard

*Correspondence: isra.ibrahim@ju.edu.jo; +96 2780669080

(Received: July 05, 2020; accepted: August 26, 2020)

Citation: Tayseer I, Azzam H, Al-Karablieh N, Mayyas A, Aburjai T. Interaction of Folk Medicinal Plants with Levofloxacin against Escherichia Coli. J Pure Appl Microbiol. 2020;14(3):1855-1861. doi: 10.22207/JPAM.14.3.24

(C) The Author(s) 2020. Open Access. This article is distributed under the terms of the Creative Commons Attribution 4.0 International License which permits unrestricted use, sharing, distribution, and reproduction in any medium, provided you give appropriate credit to the original author(s) and the source, provide a link to the Creative Commons license, and indicate if changes were made. 


\section{INTRODUCTION}

The expansion of bacterial resistance to the currently used antibiotics has necessitated the need to look for novel antibacterial agents ${ }^{1}$. Universally, Escherichia coli is a critical source of food borne illness and a threat to public health². The growing incidence of antibiotic-resistant E. coli isolates is a worldwide health concern and are currently linked with higher morbidity, mortality and usually higher care expenditure compared with strains vulnerable to antibiotics ${ }^{3}$. Fluoroquinolones have been broadly used in the genitourinary infections' management, particularly in cases of acute uncomplicated cystitis. Although fluoroquinolone resistance was infrequent among urinary tract pathogens, resistance in $E$. coli has developed and keeps rising. Levofloxacin has an inhibitory activity against different uropathogens, including E.coli ${ }^{4,5}$. Moving on now to consider that some medicinal plants produce multidrug resistance inhibitors which improve the activities of antibiotics against multidrug resistant bacteria pathogens. It is this finding that encouraged efforts in screening of medicinal plants for possible interaction with standard antibiotics against resistant bacteria as this would cover the approach for possible isolation of multidrug resistance inhibitors of plant origin. A study of this type would also help to show the class of antibiotics that could be accurately combined with certain herbal medications in ethnomedicine against certain infections ${ }^{6}$. In our previous works ${ }^{7-9}$ we have investigated the effects of numerous plants in Jordan, traditionally thought to have some antimicrobial activity on their potential antibiotic resistance-modifying activity of different antimicrobials. In this study, in vitro activity of twelve folk medicinal plants was investigated for their ability to potentiate, modify or minimize the activities of levofloxacin against $E$. coli strains. This study may highlight if traditional use of these plants for bacterial infections represent a real effect or not.

\section{MATERIALS AND METHODS Plant material}

Twelve plants were selected based on their traditional usage as folk medicine either alone or in combination with antibiotics. The plants were purchased from traditional herbal market in Amman, Jordan [Table 1].The taxonomic identification of plants was verified by comparing the voucher specimens with those of established identity which are located in the Herbarium of the Faculty of Science, The University of Jordan and with the help of a plant taxonomist. A voucher specimen was placed at the Department of Pharmaceutical Sciences, School of Pharmacy, The University of Jordan (Phytochemistry lab.).

\section{Preparation of plant extracts}

Plant materials were dried, grounded to a fine powder ( $40 \mathrm{~g}$ each) and then extracted

Table 1. Plants used in the antimicrobial testing

\begin{tabular}{lccc}
\hline Botanical species & Family & Part used & Voucher Specimen \\
\hline $\begin{array}{l}\text { Camellia sinensis } \text { L. (Kuntze) } \\
\text { Curcuma longa } \text { L. }\end{array}$ & Theaceae & Leaves & CS-118 \\
Achillea tomentosa L. & Zingiberaceae & Rhizome & CL-918 \\
Cinnamomum zeylanicum & Asteraceae & Arial parts & AT-119 \\
(Syn. Cinnamomum verum) & Lauraceae & Bark & CZ-202 \\
Zingiber officinale (Rosc.) & Zingiberaceae & Rhizome & ZO-118 \\
Thymus vulgaris L. & Lamiaceae & Leaves & TV-119 \\
Matricaria chamomilla L. & Asteraceae & Flower & MC-020 \\
$\begin{array}{l}\text { Pimpinella anisum } \text { L. } \\
\text { Salvia rosmarinus (Spenn.) }\end{array}$ & Umbellifers & Fruits & PA-202 \\
(Syn. Rosmarinus officinalis) & Lamiaceae & leaves & RO-718 \\
Artemisia jordanica (Danin) & Asteraceae & Leaves & AJ-619 \\
Teucrium polium L. & Lamiaceae & Arial parts & TP-319 \\
Salvia officinalis L. & Lamiaceae & Leaves & SO-001 \\
\hline
\end{tabular}

Syn.: synonym 
using a Soxhlet with $500 \mathrm{ml}$ of $95 \%$ ethanol for 4 hrs. A rotary evaporator was used to concentrate the extract under reduced pressure and heating below $40^{\circ} \mathrm{C}$. The dried crude extract was weighed and dissolved in ethanol to get $10 \mathrm{mg} / \mathrm{ml}$ concentration, and stored in amber tubes and placed under $4^{\circ} \mathrm{C}$ for extra experiments.

\section{Bacterial strains and growth conditions}

E. coli wild-type TG1 strain (ATCC 25922) and a mutant strain KAM3-1( $\Delta a c r B-\Delta t o l C)$ were used for this study, maintained routinely at $37^{\circ} \mathrm{C}$ on Luria-Bertani medium for $24 \mathrm{hrs}$. Bacterial subcultures were suspended in nutrient broth, supplemented with $15 \%$ glycerol and stored at $-70^{\circ} \mathrm{C}$ for further use ${ }^{10}$.

\section{Antimicrobial tests}

MICs Determination

MIC of plant extracts as well as levofloxacin

(Dar Al-Dawa Pharmaceutical Manufacture, Amman, Jordan) was determined by 96 -well micro-dilution method. Agar diffusion assay was not performed because it could not always be reliable for plant extracts as the natural active compounds are not polar enough to easily diffuse in the aqueous agar matrix ${ }^{11}$ and since MIC is required for the following assays, broth dilution was performed. Experiments were carried out in triplicate in accordance with the recommendations of the National Center for Clinical Laboratory Standards ${ }^{12}$. Ethanol was used as a negative control while levofloxacin was used as a positive control. The 1st well was aliquoted with $180 \mu \mathrm{l}$ of Mueller-Hinton broth (MHB) (Biolab, Budapest, Hungary) whereas, $100 \mu \mathrm{L}$ of $\mathrm{MHB}$ was added to the 2 nd - 10th well. In the 1st row of the plate, $20 \mu \mathrm{l}$ from the stock solution of plant extracts (10 $\mathrm{mg} / \mathrm{ml}$ ) was added. Then, 2-fold serial dilutions were done using a micropipette. Each well was inoculated with $100 \mu \mathrm{l}$ of approximately 1 McFarland standard of freshly grown bacteria, making the final concentration in the wells in the range $(1000-7.81 \mu \mathrm{g} / \mathrm{mL})$. Regarding levofloxacin, the final concentration range used to determine MIC was (1- $0.00781 \mu \mathrm{g} / \mathrm{ml})$. The MIC values were obtained visually after incubation of the inoculated 96 well plates at $37^{\circ} \mathrm{C}$ for 24 hours, as the minimum concentration that led to bacterial growth inhibition.

\section{Determination of combination interaction using microdilution checkerboard method}

The checkerboard broth microdilution method was used for determination of the effect of combinations of levofloxacin and the selected plant extracts with efficient MIC on 96-well plates with a final volume of $200 \mu \mathrm{l}$ in each well, as described the literature ${ }^{13-15}$. Briefly, 2-fold dilutions of both levofloxacin and plant extracts was used for the assay before testing. Stock solutions of $10 \mu \mathrm{g} / \mathrm{ml}$ of levofloxacin and $10 \mathrm{mg} / \mathrm{ml}$ of plant extracts were used. The levofloxacin was serially diluted over the $x$-axis while the plant extracts was diluted over the y-axis [Fig. 1]. The used inoculum concentration and incubation conditions were as in MIC determination method. Control sample containing the solvent with $\mathrm{MHB}$ and the bacteria was used. Each experiment was performed in triplicate.

As mentioned earlier, the combination MIC was determined with the minimum concentration at which no turbidity was observed. The data resulted by the checkerboard method were evaluated in terms of the fractional inhibitory concentration index ( $\mathrm{FICl}$ ) and calculated for each combination using the formula in [Fig. 2]:

\section{RESULTS AND DISCUSSION}

Plants have been used by many cultures to treat many conditions since they are natural, non-toxic, and inexpensive sources of drug. It is well known that many communities use herbal brews during antibiotics treatment believed that this well augment the effects of these antibiotics. Levofloxacin is among the recent antibiotics used for treatment of different infectious diseases mainly those induced by $E$. coli $i^{5}$. It is noteworthy to mention that many people increase their consumption of certain plants brew during levofloxacin therapy as well as other antibiotics. Based on this and to examine possible drugherb interaction, it was important to examine scientifically the possible interaction between levofloxacin and the most common plant used in combination with it.

The addition of certain herbal remedies and diverse antibiotics may affect the activity of these antibiotic ${ }^{17}$. This study investigated the 
antimicrobial activity and interaction between different plant extracts and levofloxacin.

Antimicrobial activity of tested plants

The results of the antimicrobial activity of the tested plant extracts are presented in [Table 2]. Among all plant extracts studied, T. polium, $T$. vulgaris, C. longa, M. chamomilla and Z. officinalis showed the lowest MIC values against the E. coli wild-type TG1 $(250 \mu \mathrm{g} / \mathrm{ml})$. These findings are in accordance with previous studies ${ }^{18-22}$. On the other hand, other plant extracts didn't show any noteworthy inhibition against this strain (MIC $>1000 \mu \mathrm{g} / \mathrm{ml}$ ).

On the other hand, The mutant strain E.coli KAM3-1( $\Delta a c r B-\Delta t o / C)$ showed increment susceptibility profile for levofloxacin. Moreover, the susceptibility pattern of the mutant strain showed similar results for the wild type when the tested plants examined.

While many of these plants' antimicrobial activity was studied earlier, their interaction with levofloxacin is not widely explored yet.

Interaction of plant extracts with levofloxacin

In this study, Checkerboard Assay was performed to study the possible synergistic activity between levofloxacin and the ethanolic extract of selected medicinal plants. Among these plants five were chosen based on their inhibitory activity

Table 2. Antimicrobial activity of plants against E.coli strains $(\mu \mathrm{g} / \mathrm{ml})^{*}$

\begin{tabular}{lcc}
\hline \multirow{2}{*}{ plant } & \multicolumn{2}{c}{ Microorganisms } \\
\cline { 2 - 3 } & $\begin{array}{c}\text { E. coli wild-type } \\
\text { TG1 }\end{array}$ & $\begin{array}{c}\text { E. coli KAM3-1 } \\
(\Delta \text { AcrB- } \Delta \text { tolC })\end{array}$ \\
\cline { 2 - 3 } & \multicolumn{2}{c}{ MIC $(\mu \mathrm{g} / \mathrm{ml})$} \\
\hline C. sinensis & $>1000$ & $>1000$ \\
C. longa & 250 & 250 \\
A. tomentosa & $>1000$ & $>1000$ \\
C. zeylanicum & $>1000$ & $>1000$ \\
Z. officinale & 250 & 250 \\
T. vulgaris & 250 & 250 \\
M. chamomilla & 250 & 250 \\
P. anisum & $>1000$ & $>1000$ \\
R. officinalis & $>1000$ & $>1000$ \\
A. jordanica & $>1000$ & $>1000$ \\
T. polium & 250 & 250 \\
S. officinalis & $>1000$ & $>1000$ \\
Levoflaxacin & 0.03125 & $<0.0078$ \\
\hline
\end{tabular}

*Experiments were conducted in triplicate.

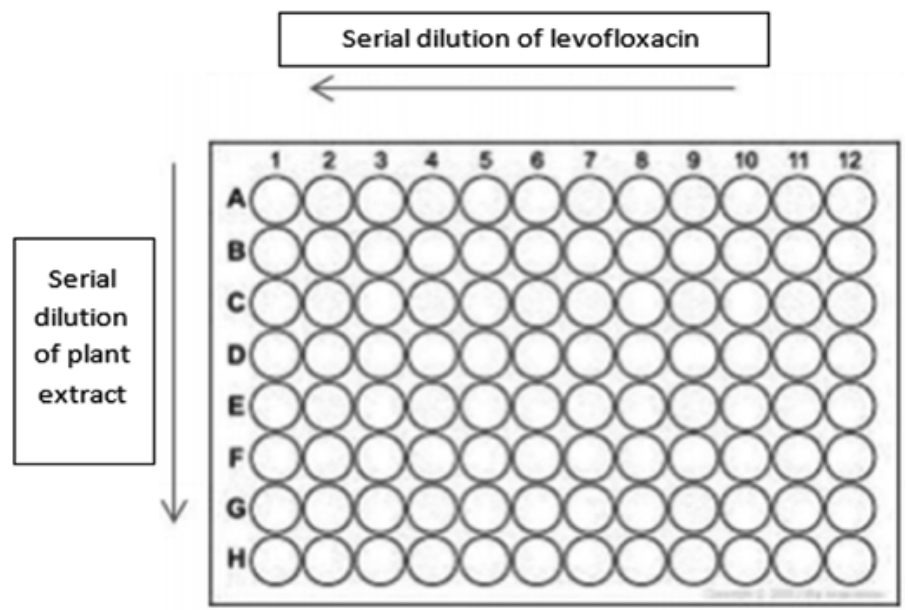

Fig. 1. Checkerboard method for Determination of the effect of the combination on $E$. coli

FICI $=\left[\begin{array}{ccc}\text { MIC of plant extract in combination } & + \text { MIC of levofloxacin in combination } \\ \text { MIC of plant extract alone } & \text { MIC of levofloxacin alone }\end{array}\right]$

Fig. 2. $\mathrm{FICl}$ calculation formula

The results were analyzed as follows: synergy, $\mathrm{FICl}$ of $\leq 0.5$; additivity, $\mathrm{FICl}$ of $>0.5$ to $\leq 1$; no interaction (indifference), $\mathrm{FICl}$ of $>1$ to $\leq 4$; antagonism, $\mathrm{FICl}$ of $>4 \cdot{ }^{13,16}$ 
Table 3. antimicrobial interaction of plant extracts and levofloxacin combination*

\begin{tabular}{lcccc}
\hline Plant extracts & FIC of plant & FIC of levofloxacin & FICl & Interpretation \\
\hline C. longa & 0.062 & 2 & 2.062 & Indifference \\
T. polium & 0.015 & 0.499 & 0.515 & Additive \\
M. chamomilla & 0.015 & 2 & 2.015 & Indifference \\
T. vulgaris. & 0.015 & 0.499 & 0.515 & Additive \\
Z. officinalis & 0.125 & 1 & 1.125 & Indifference \\
\hline
\end{tabular}

*Experiments were conducted in triplicate.

against E. coli wild-type TG1. An overview of FIC index details is shown in [Table 3]. The antimicrobial interaction of levofloxacin in combination with $T$. polium or T. vulgaris against E.coli strains showed additive effect. On the other hand, no interaction in C. longa, M. chamomilla and Z.officinalis combinations was detected. Moreover, neither synergistic nor antagonistic effects were observed when these plants combined with levofloxacin.

A possible explanation for the obtained results [Table 3] might be that these plant extracts have numerous phytochemicals which might inhibit bacterial growth by different mechanisms. Various Studies have investigated the ability of many plant-derived compounds to affect the antimicrobial resistance pattern ${ }^{23,24}$. It has been shown that many of these compounds exert their antimicrobial activity over membrane disturbances, such as polyphenols ${ }^{25}$. Some of these compounds can also produce a specific peptidoglycan inhibiting antibiotics activity by targeting the same site in the cell wall ${ }^{26}$. Among pathogenic bacteria, efflux pumps are accountable for a significant degree of resistance to antibiotics ${ }^{27}$. Some phytochemicals were identified to boost the efficacy of antimicrobial agents by inhibiting bacterial multidrug resistance efflux systems ${ }^{28}$.

Previous studies revealed that triterpenes, flavonoids and tannins were present in T. polium and $T$. vulgaris extracts ${ }^{29,30}$. Flavonoids, one of the broadest classes of phenolic compounds, has been found to permeabilize the outer membranes of Gram-negative bacteria ${ }^{31}$, which might contribute to enhanced uptake of levofloxacin. In addition, some flavonoids have demonstrated an inhibitory activity against $E$. coli DNA gyrase ${ }^{32}$, which would inprove the antibacterial activity of levofloxacin. On the other hand, Alkaloids that are present in T. polium might disrupt the bacterial outer membrane, affect the cell division by inhibiting the nucleic acid synthesis, and inhibiting the efflux pump or down regulation of efflux pump genes, working together to improve levofloxacin activity ${ }^{33}$.

Therefore, the various modes of action of the medicinal plants from the antibiotics seems to be a significant aspect in the augmented bactericidal activity noted when used in grouping. Meanwhile the combinations of plant extracts with antibiotics might inhibit Gram negative bacteria, and some combinations might be additive, synergistic or indifferent, these combinations may be applied and favorable in inhibiting bacteria.

Moreover, using such antibiotics in combination will reduce the prescribed dose lower than when used alone, which may extra minimize the incidence of adverse effects induced by these antibiotics. Testing crude extracts for such activities is the initial step in recognizing those compounds in plants that have strong potentials for use in combination with antibacterial. Further isolation and purification of the crude extracts might show an improvement in bioactivity than the crude extracts.

\section{CONCLUSION}

Additive interaction was observed when levofloxacin combined with T. polium or T. vulgaris against E.coli wild-type strain while no interaction was noted with $C$. longa, M. chamomilla and Z.officinalis. Further clinical studies are required to ensure the effectiveness of plant extracts in vivo. Our study suggests the possibility of concomitant use of levofloxacin and plants in the treatment of infections caused by $E$. coli or at least that the concurrent administration of these plants with levofloxacin will not diminish the antimicrobial activity of it. 


\section{ACKNOWLEDGMENTS}

The authors would like to thank the Deanship of Scientific Research and Hamdi-Mango Center for Scientific Research, The University of Jordan, Amman-Jordan, for financial and technical support. We would like to express our heartfelt thanks to Professor Sawsan Al-Oran, a plant taxonomist, for providing assistance in the taxonomic identification of collected plant specimens. Thanks also to Dar Al-Dawa manufacture for the supply of levofloxacin.

\section{CONFLICT OF INTEREST}

The authors declare that there is no conflict of interest.

\section{AUTHORS' CONTRIBUTION}

All authors listed have made a substantial, direct, and intellectual contribution to the work, and approved it for publication.

\section{FUNDING}

This work was supported by Deanship of Scientific Research, University of Jordan, Amman, Jordan. Grant number (4009).

\section{ETHICS STATEMENT}

Not applicable.

\section{DATA AVAILABILITY}

All datasets analyzed in the study are included in the manuscript and presented as tables.

\section{REFERENCES}

1. Amenu D. Antimicrobial activity of medicinal plant extracts and their synergistic effect on some selected pathogens. American Journal of Ethnomedicine. 2014;1(1):18-29.

2. Kariuki S, Dougan G. Antibacterial resistance in subSaharan Africa: an underestimated emergency. Ann N Y Acad Sci. 2014;1323(1):43-55. doi: 10.1111/ nyas. 12380

3. Aworh MK, Kwaga J, Okolocha E, Mba N, Thakur S. Prevalence and risk factors for multi-drug resistant Escherichia coli among poultry workers in the Federal Capital Territory, Abuja, Nigeria. PLoS One. 2019;14(11):e0225379. doi: 10.1371/journal. pone.0225379

4. McGregor JC, Allen GP, Bearden DT. Levofloxacin in the treatment of complicated urinary tract infections and acute pyelonephritis. Ther Clin Risk Manag. 2008;4(5):843-853. doi: 10.2147/TCRM.S3426
Al-Tamimi M, Abu-Raideh J, Albalawi H, Shalabi M, Saleh S. Effective oral combination treatment for extendedspectrum beta-lactamase-producing Escherichia coli. Microbial Drug Resistance. 2019;25(8):1132-41. doi: 10.1089/mdr.2019.0065

6. Eze EA, Oruche NE, Eze CN. Interaction of the extracts of three medicinal plants with antibiotics against some antibiotic resistant bacteria. Scientific Research and Essays. 2013;8(28):1360-1367. doi: 10.5897/ SRE2013.5515

7. Darwish RM, Aburjai TA. Effect of ethnomedicinal plants used in folklore medicine in Jordan as antibiotic resistant inhibitors on Escherichia coli. BMC Complement Altern Med. 2010;10:9.doi: 10.1186/1472-6882-10-9

8. Aburjai T, Darwish RM, Al-Khalil S, Mahafzah A, Al-Abbadi A. Screening of antibiotic resistant inhibitors from local plant materials against two different strains of Pseudomonas aeruginosa. J Ethnopharmacol. 2001;76(1):39-44. doi: 10.1016/ S0378-8741(01)00206-9

9. Darwish RM, Aburjai T, Al-Khalil S, Mahafzah A. Screening of antibiotic resistant inhibitors from local plant materials against two different strains of Staphylococcus aureus. J Ethnopharmacol. 2002;79(3):359-364. doi: 10.1016/S03788741(01)00411-1

10. Al-Karablieh N, Weingart H, Ullrich MS. Genetic exchange of multidrug efflux pumps among two enterobacterial species with distinctive ecological Niches. Int J Mol Sci. 2009;10(2):629-645. doi: 10.3390/ ijms10020629

11. Klancnik A, Piskernik S, Jersek B, Mozina SS. Evaluation of diffusion and dilution methods to determine the antibacterial activity of plant extracts. J Microbiol Methods. 2010;81(2):121-126. doi: 10.1016/j. mimet.2010.02.004

12. National Committee for Clinical Laboratory Standards (NCCLS) Performance standards for antimicrobial disk and dilution susceptibility tests for bacteria isolated from animals. Pennsylvania: NCCLS; 2013: M100-S23.

13. Sopirala MM, Mangino JE, Gebreyes WA, et al. Synergy testing by Etest, microdilution checkerboard, and time-kill methods for pan-drug-resistant Acinetobacter baumannii. Antimicrob Agents Chemother. 2010;54(11):4678-4683. doi: 10.1128/AAC.00497-10

14. Rabadia A, Kamat S, Kamat D. Study of synergistic action of cefotaxime and Terminalia chebula on Acinetobacter baumannii using checkerboard assay. Int J Pharm Pharm Sci. 2013;5:830-2.

15. Moody JA. Synergy testing: broth microdilution checkerboard and broth macrodilution methods. In H. D. Eisenberg (ed.), Clinical microbiology procedures handbook. American Society for Microbiology, Washington, DC. 1992:5.18.1-5.18.23.

16. Petersen PJ, Labthavikul P, Jones $\mathrm{CH}$, Bradford PA. In vitro antibacterial activities of tigecycline in combination with other antimicrobial agents determined by chequerboard and time-kill kinetic analysis. J Antimicrob Chemother. 2006;57(3):573-576. doi: 10.1093/jac/dki477

17. Adwan G, Mhanna M. Synergistic effects of plant 
extracts and antibiotics on Staphylococcus aureus strains isolated from clinical specimens. Asian Pacific Journal of Tropical Medicine. 2009;2(3):46-51.

18. Darabpour E, Motamedi H, Nejad SMS. Antimicrobial properties of Teucrium polium against some clinical pathogens. Asian Pacific Journal of Tropical Medicine. 2010;3(2):124-127. doi: 10.1016/S19957645(10)60050-8

19. Gul P, Bakht J. Antimicrobial activity of turmeric extract and its potential use in food industry. J Food Sci Technol. 2015;52(4):2272-2279. doi: 10.1007/s13197013-1195-4

20. Abdalla RM, Abdelgadir AE. Antibacterial activity and phytochemical constituents of Cinnamomum verum and Matricaria chamomilla from Sudan. Bio Bulletin. 2016;2(2):01-10.

21. Njobdi S, Gambo M, Ishaku GA. Antibacterial Activity of Zingiber officinale on Escherichia coli and Staphylococcus aureus. Journal of Advances in Biology \& Biotechnology. 2018:1-8. doi: 10.9734/ jabb/2018/43534

22. Mohsenipour Z, Hassanshahian M. The inhibitory effect of Thymus vulgaris extracts on the planktonic form and biofilm structures of six human pathogenic bacteria. Avicenna J Phytomed. 2015;5(4):309-318.

23. Sato $M$, Tanaka $H$, Yamaguchi R, Kato K, Etoh $H$. Synergistic effects of mupirocin and an isoflavanone isolated from Erythrina variegata on growth and recovery of methicillin-resistant Staphylococcus aureus. Int J Antimicrob Agents. 2004;24(3):241-246. doi: 10.1016/j.ijantimicag.2004.03.020

24. Cushnie TP, Lamb AJ. Antimicrobial activity of flavonoids [published correction appears in Int $J$ Antimicrob Agents. 2006;27(2):181]. Int J Antimicrob Agents. 2005;26(5):343-356. doi: $10.1016 / \mathrm{j}$. ijantimicag.2005.09.002

25. Aiyegoro O, Adewusi A, Oyedemi S, Akinpelu D, Okoh A. Interactions of antibiotics and methanolic crude extracts of Afzelia Africana (Smith.) against drug resistance bacterial isolates. Int J Mol Sci. 2011;12(7):4477-4503. doi: 10.3390/ijms12074477

26. Zhao WH, Hu ZQ, Okubo S, Hara Y, Shimamura T. Mechanism of synergy between epigallocatechin gallate and beta-lactams against methicillin-resistant Staphylococcus aureus. Antimicrob Agents Chemother. 2001;45(6):1737-1742. doi: 10.1128/AAC.45.6.17371742.2001

27. Kumar A, Schweizer HP. Bacterial resistance to antibiotics: active efflux and reduced uptake. Adv Drug Deliv Rev. 2005;57(10):1486-1513. doi: 10.1016/j. addr.2005.04.004

28. Tegos G, Stermitz FR, Lomovskaya O, Lewis K. Multidrug pump inhibitors uncover remarkable activity of plant antimicrobials. Antimicrob Agents Chemother. 2002;46(10):3133-3141. doi: 10.1128/aac.46.10.31333141.2002

29. Darabpour E, Motamedi H, Nejad SMS. Antimicrobial properties of Teucrium polium against some clinical pathogens. Asian Pacific Journal Of Tropical Medicine. 2010;3(2):124-127.doi: 10.1016/S19957645(10)60050-8

30. Nascimento GGF, Locatelli J, Freitas PC, Silva GL. Antibacterial activity of plant extracts and phytochemicals on antibiotic-resistant bacteria. Braz J Microbiol. 2000;31(4):247-256. doi: 10.1590/S151783822000000400003

31. Prasad MA, Zolnik CP, Molina J. Leveraging phytochemicals: the plant phylogeny predicts sources of novel antibacterial compounds. Future Sci OA. 2019;5(7):FSO407. 2019. doi: 10.2144/fsoa-2018-0124

32. Kumar S, Pandey AK. Chemistry and biological activities of flavonoids: an overview. Scientific World Journal. 2013;2013:162750. 2013 Dec 29. doi: $10.1155 / 2013 / 162750$

33. Othman L, Sleiman A, Abdel-Massih RM. Antimicrobial Activity of Polyphenols and Alkaloids in Middle Eastern Plants. Front Microbiol. 2019;10:911. doi: 10.3389/ fmicb.2019.00911 